\title{
Gerenciamento de crises no setor público e suas influências sobre a administração: o caso da Operação Voucher no Ministério do Turismo
}

\author{
Bruna Ribeiro da Silva \\ Universidade de Brasília (UnB) \\ Helena Araújo Costa \\ Universidade de Brasilia (UnB)
}

O estudo teve como objetivo analisar a crise ocorrida em 2011, em decorrência da Operação Voucher, no Ministério do Turismo (MTur) e seu gerenciamento, bem como os impactos positivos e negativos decorrentes sobre a gestão do órgão. Para tanto, foi realizado um estudo de caso no MTur em que se procurou relatar os antecedentes e as fases da crise em estudo, descrever a forma como o órgão lidou com ela e verificar os impactos positivos e negativos dela sobre a gestão do órgão, dando enfoque nas cinco funções da administração. A pesquisa teve abordagem qualitativa e contou com a aplicação de um roteiro de entrevista semiestruturado junto a sete respondentes-chave, identificados com auxílio da técnica do Snowball. A análise de dados foi realizada de acordo com a técnica de análise de conteúdo. Os resultados encontrados revelaram que a citada crise apresentou impactos nas seguintes funções da administração: planejamento, organização, controle, execução e liderança. Foram identificados impactos negativos, tais como o acúmulo e atraso das demandas a serem resolvidas, a insegurança e as relações de trabalho estremecidas, que contribuem para um ambiente e clima organizacional desconfortáveis. Por outro lado, também revelaram-se impactos positivos, tais como melhorias no controle dos processos por meio da implantação de ferramentas e maior responsabilidade por parte dos servidores com o que é público, contribuindo para o fortalecimento da estrutura organizacional.

Palavras-chave: gestão de crise, setor público - Brasil, estudo de caso - Ministério do Turismo

[Artigo recebido em 13 de abril de 2017. Aprovado em 19 de fevereiro de 2018.] 


\section{Gestión de crisis en el sector público e influencias en gestión: el caso de la Operación de} Bono en el Ministerio de Turismo

El estudio pretende analizar la crisis en 2011, debido a la operación de bono en el Ministerio de Turismo (MTur) y su gestión, así como los impactos positivos y negativos resultantes sobre la gestión de la agencia. Para ello, se realizó un estudio de caso en el MTur en el que se intentó relatar el fondo y las etapas de la crisis en estudio, describir cómo la agencia lidió con ella y comprobar sus impactos positivos y negativos en la gestión del órgano, dando énfasis en cinco funciones de administración. La encuesta tuvo un enfoque cualitativo y la implementación de un plan de entrevista guía para los siete encuestados clave, identificados mediante la técnica de Snowball. El análisis de los datos se realizó según la técnica de análisis de contenido. Los resultados mostraron que la citada crisis presenta impactos en las siguientes funciones de gestión: planificación, organización, control, ejecución y liderazgo. Se identificaron impactos negativos, como la acumulación y retraso de las demandas a ser resueltas, la inseguridad y de las relaciones de trabajo estremecidas, contribuyendo a un ambiente y un clima organizacional incómodos. Por otra parte, resultó haber también impactos positivos, como mejoras en el control de procesos mediante la implementación de herramientas y una mayor responsabilidad por parte de los servidores públicos, con lo que se contribuye al fortalecimiento de la estructura organizacional.

Palabras clave: gestión de crisis, sector público, estudio de caso - Ministerio del Turismo

Crisis management in the public sector and its influences on the administration: the case of the Voucher Operation in the Ministry of Tourism

The study aimed to analyze the crisis in 2011, due to the Voucher Operation in the Ministry of tourism (MTur) and its management, as well as the positive and negative impacts arising on the management of the agency. To this end, we conducted a case study in the MTur in which we sought to report the antecedents and the phases of the crisis, describe how the agency dealt with it and check its positive and negative impacts on the management of the organ, giving focus on five functions of administration. The study had a qualitative approach and the implementation of a roadmap of interview semi-structured with 7 key responders, identified with the help of Snowball technique. Data analysis was performed according to the technique of content analysis. The results showed that the crisis has presented impacts on the following administration functions: planning, organization, control, execution and leadership. Negative impacts have been identified such as the accumulation and backwardness of the demands to be resolved, insecurity and the strained labor relations, contributing to an uncomfortable environment and organizational climate. On the other hand, also was proved positive impacts such as improvements in the control of processes by deploying tools and greater responsibility on the part of the servers with what that is public, contributing to the strengthening of the organizational structure.

Keywords: crisis management, public sector - Brazil, case study - Ministry of Tourism 


\section{Introdução}

Crise é um termo popular usado com frequência em uma ampla variedade de contextos. Ela pode ser conceituada como um período de descontinuidade, marcando o ponto de ruptura em um processo padronizado de linearidade (BoIN, 2004). Outros autores ressaltam que crise consiste em algo maior do que um conjunto de problemas (OLIVEIRA, 2014), como um acontecimento capaz de produzir perturbações nos mais variados níveis de uma organização (CARVALHO, 2014).

As crises organizacionais são imprevisíveis e ocorrem quando a estrutura organizacional de um sistema social experimenta um forte declínio de legitimidade (SANTOS, 2012). Quanto à natureza das crises organizacionais, vários tipos de crises podem afetar as organizações, revelando as vulnerabilidades às quais são expostas: extorsão, suborno, aquisição hostil, sabotagem de informações, adulteração de computador, boatos mal-intencionados, falsificações etc. (PEARSON; CLAIR, 1998). Assim, a pesquisa aqui apresentada aplica esses conceitos para o universo organizacional, em especial para o contexto das organizações públicas federais, como o MTur.

Academicamente, o tema recebe contribuições de disciplinas como a Sociologia, Administração Pública, Ciências Políticas e Relações Internacionais, Psicologia Política e Organizacional, entre outras. Crises econômicas, políticas e institucionais têm sido assuntos recorrentes nos noticiários nacionais ${ }^{1}$, agravadas por uma percepção de baixa qualidade na oferta de serviços públicos, fragilidade no controle e na transparência dos processos, e escândalos de corrupção na gestão pública (PEREIRA, 2014). Apesar dessa presença cotidiana do tema e da relevância no contexto jornalístico, ainda é limitada a produção acadêmica nacional acerca dele no contexto da gestão. Como ilustração, nos últimos 10 anos (2007 - 2017), apenas 12 artigos publicados pela Revista de Administração Pública (RAP) e apenas 2 na Revista de Administração de Empresas (RAE) traziam a palavra crise em seu título. Ainda assim, nenhum deles tratava da gestão de crises em si como problema central.

$\mathrm{Na}$ literatura especializada em turismo, por sua vez, as abordagens variam e dizem respeito a crises geradas por fenômenos naturais (MOORE, 2010), terrorismo (HALL, 2010), questões políticas (COHEN; NEAL, 2010), aspectos macroeconômicos ligados a recessão, inflação, desemprego, entre outros, especialmente em relação com o impacto na visitação de determinados destinos (LI; BLAKE; COOPER, 2010), tais como China (LI; BLAKE; COOPER, 2010), Tailândia (COHEN; NEAL, 2010) e Islândia (JóHANNESSON; HUIJBENS, 2010). Do ponto de vista organizacional no

\footnotetext{
${ }^{1}$ As referências que remetem a textos jornalísticos encontram-se na lista de referências no final do artigo.
} 
setor de turismo, encontraram-se contribuições sobre a importância da liderança e da comunicação, bem como da detecção de sinais de crise nas organizações (KÁdÁrová et al., 2015; PARASKeVAS; ALtinaY, 2013; PARASKeVAs et al., 2013; RITCHIE, 2004). Todavia, a gestão de crises do ponto de vista de organizações públicas permanece pouco explorada, o que reforça a relevância da abordagem apresentada por este estudo.

Partindo do contexto colocado, o objetivo do artigo é analisar a crise ocorrida em 2011 no Ministério do Turismo, deflagrada pela Operação Voucher da Polícia Federal, e seu gerenciamento, bem como os impactos positivos e negativos dela decorrentes sobre a administração do órgão. Assim, caracterizou-se a crise em estudo (relatando seus antecedentes e fases), descreveu-se a forma como o órgão, na figura de seus gestores, técnicos e servidores, lidou com a crise, e verificaram-se os impactos positivos e negativos dela sobre a gestão do órgão, dando enfoque nas cinco funções da administração: planejamento, organização, execução, controle e liderança, segundo Maximiano (2008).

O Ministério do Turismo, lócus deste estudo, foi criado pela Lei no 10.683, de 28 de maio de 2003, tem como objetivo fomentar a política nacional de desenvolvimento do turismo, promover e divulgar o turismo nacional no país e no exterior, estimular as iniciativas públicas e privadas de incentivo às atividades turísticas, entre outros fins (BRASIL, 2015). O caso analisado neste estudo remete à crise deflagrada com a Operação Voucher, da Polícia Federal, que investigava possíveis casos de corrupção no MTur em 2011. Na época, o órgão era responsável pela capacitação de 300 mil pessoas para a Copa do Mundo de 2014 por meio do programa Bem Receber Copa (BRC). A partir disso, viu-se a necessidade de realizar parcerias para que fosse possível atingir a meta proposta. Contudo, foram constatadas fraudes em convênios, o que impulsionou a crise que surgiu no Ministério, mais precisamente no Departamento de Qualificação (atualmente extinto).

O artigo foi então estruturado em quatro seções, além desta introdução. O referencial teórico foi apresentado na segunda seção, abordando o conceito de crise, sua relação com a comunicação e com a gestão, bem como os impactos das crises sobre a gestão das organizações. A terceira seção apresenta os aspectos metodológicos do estudo, seguida pela quarta seção, que apresenta o contexto da Operação Voucher e os resultados; e por último, a quinta seção, que apresenta as considerações finais. 


\section{Crise: conceitos, gerenciamento e impactos sobre a administração das organizações}

Apesar de não haver consenso sobre o conceito de crise, é recorrente atribuir a ela o sentido de "fase grave, complicada, difícil, um momento de tensão ou de impasse na vida de uma pessoa, de um grupo social, na evolução de determinadas situações" (MENDES, 2005, p. 766), podendo ser desdobrada em outras para os diferentes agentes envolvidos, conforme as interpretações, associações, acusações e argumentações que recaem sobre cada um (MENDES, 2005), ou um estado de fluxo durante o qual as estruturas institucionais em um sistema social se desenraizaram, cuja principal moeda é a legitimidade (BoıN, 2004).

Dentro da literatura, aparece uma variedade de crises: financeiras (KRUGMAN, 2010; BRESSER, 1996); políticas (MENDES, 2005); de legitimidade, moral (BRESSER, 1996); de imagem (NASCIMENTO, 2007), epidemias (ShARPLEY; CrAVEN, 2001), catástrofes industriais ou naturais, falhas em equipamentos e construções, de natureza legal, de relações humanas, de risco de vida e regulatórias (ROSA, 2003).

No turismo, o aspecto mais encontrado nas publicações refere-se ao impacto de crises, das mais distintas esferas, sobre a demanda por determinados destinos turísticos (SharPleY; CRAVEN, 2001; PARASKeVAs et al.; 2013). Ritchie (2004) enfatiza que o mundo, cada vez mais interdependente e conectado, possibilita que crises de pequeno porte em uma determinada parte do mundo gerem um impacto significativo em outros lugares. Este trabalho, por sua vez, propõe uma abordagem diferente ao manter sua atenção sobre uma crise de cunho político-institucional e no contexto da administração pública.

Gladu (2003) destaca a importância da distinção entre crise e emergência no serviço público, definindo a emergência como uma situação anormal que requer uma ação imediata para limitar os danos às pessoas, bens ou o ambiente. Já a crise é entendida como uma situação que, de alguma forma, desafia o sentido público de adequação, tradição, valores, segurança e a integridade do governo. Sendo assim, as crises podem ser oriundas de emergências parcialmente resolvidas. Por outro lado, podem ser desencadeadas simplesmente por falhas aparentes nas políticas, regulamentos ou programas. A crise no setor público, de acordo com Gladu (2003), implica:

- Focar em questionamentos fundamentais de um problema (real ou percebido).

- Ter um problema de alcance muito extenso.

- Ter perda de confiança do público nas instituições. 
- Extensa mobilização no que diz respeito à gestão de operações e comunicações.

- Concentrar-se na restauração, confiança e na busca de um consenso.

Farazmand (2001) aponta para a necessidade de uma maior abordagem sobre o tema, já que a gestão de crises é vista como uma função imprescindível e atual da administração pública. O autor afirma que a prática da administração de emergência está cada vez mais corrente, e que ambas exigem visão estratégica de longo prazo e pensamento criativo a serviço do bem comum, levando ao envolvimento de todos os pertencentes à comunidade. De modo sistemático, a gestão bem sucedida da crise implica em dar um sentindo de urgência à questão; bem como pensar de forma criativa e estratégica para resolver a crise, tomar ações ousadas, agindo com coragem e sinceridade; romper com a cultura organizacional de autoproteção, assumindo riscos e ações que possam produzir melhores soluções nas quais não haveria perdedores significativos; e, por fim, realizar a manutenção de uma presença contínua na situação que muda rapidamente com o desenrolar dos eventos (FARAZMAND, 2001).

É possível observar na literatura internacional o destaque dado à liderança como aspecto crucial da gestão de crises do ponto de vista organizacional, enfatizando sua importância nas resoluções de crise (GLADU, 2003; FARAZMAND, 2001; BALSER; FoXMAN, 2005; BoIn et al., 2005). Santos, Mello e Cunha (2016) abordam o termo sensemaking, ou "criação de sentido", ressaltando que os líderes devem ter a capacidade de reconhecer que algo fora do comum está em desenvolvimento na organização.

Além de conhecer profundamente sua organização, frente a uma situação de crise o gestor é chamado a conduzi-la de forma resiliente ao ambiente, realizando o que Sobral e Peci (2008) chamam de equalização. Para operar nessa conjuntura, algumas habilidades passam a ser requeridas. Entre elas, o líder precisa ser perceptivo, intuitivo, possuidor de domínio em diversos campos, capaz de assumir responsabilidades adicionais, capaz de pensar claramente, decisivo e capaz de manter a calma sob pressão (GLADU, 2003). Outra questão ressaltada diz respeito à criação de uma equipe para a gestão da crise, assim como à existência de um planejamento estratégico nas instituições, com fases distintas e claras, capaz de ser um forte instrumento em momentos turbulentos, sendo que sua atuação não se restringe apenas ao momento de crise, mas refere-se também tanto ao momento que a antecede quanto ao momento pós-crise.

A gestão de crises pode ser organizada em quatro fases: mitigação, preparação, resposta e recuperação, sendo essencial a distinção das mesmas para a resolução 
da crise. Cada fase está associada a um momento no desdobramento da crise, conforme ilustra a Figura 1 (GLADU, 2003).

Figura 1 - 0 processo de gerenciamento de crises e emergências

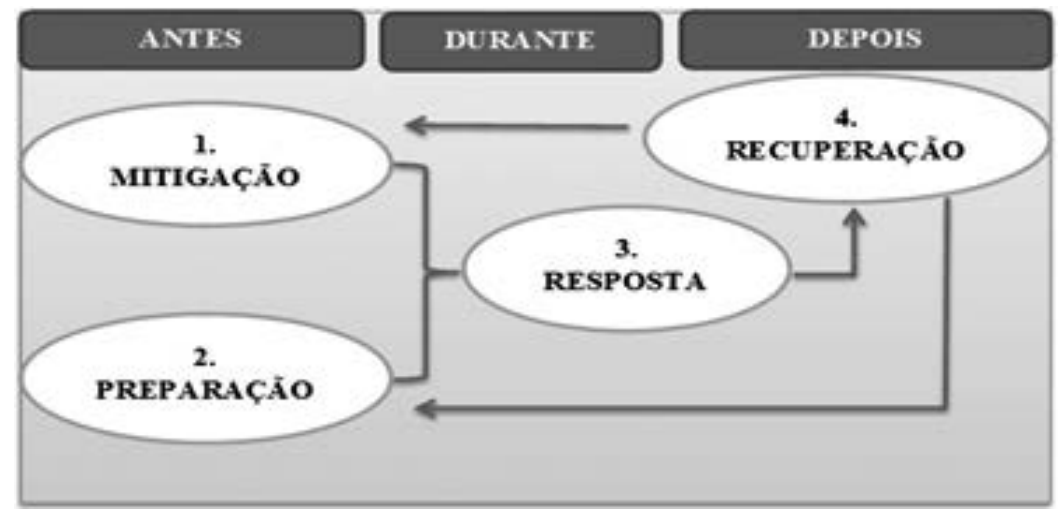

Fonte: Elaborado a partir de Gladu (2003).

Na primeira fase, mitigação, as medidassãotomadas para reduzir as consequências de uma crise ou emergência. Sendo assim, cabe nessa fase a condução de uma revisão, a avaliação de riscos, o estudo de um pior cenário, o estudo de situações anteriores, a organização para especialização e uma configuração contínua de sistemas de monitoramento. Na segunda fase, preparação, tomam-se medidas para preparar-se para crise efetiva ou para uma resposta de emergência. Logo, busca-se desenvolver planos de operação e comunicação, formar uma equipe para resolução da crise, designar parceiros, criar sistemas e treinar e exercer os planos. A terceira fase, voltada para respostas, deve fornecer as medidas tomadas para lidar com as consequências de uma crise ou uma emergência, ou seja, avaliar a situação, ativar o plano operacional e ativar o plano de comunicação. Por fim, a quarta e última fase, a recuperação, é responsável por medidas tomadas no respaldo de uma crise ou emergência, como declarar o fim da crise ou da emergência (voltar às operações normais), manter a comunicação com mídia e parceiros, dar apoio aos empregados e avaliar e tirar lições a partir da experiência, que envolve o processo de liderança durante a crise, discutido por Paraskevas et al. (2013).

Parte das referências acerca de gestão de crises foi encontrada na literatura ligada à comunicação organizacional e relações públicas, como Rosa (2003), Nascimento (2007), Lourenço e Marchiori (2011), Balser e Foxman (2005), Farazmand (2001). Um dos elementos destacados por Balser e Foxman (2005) é a importância de haver uma cultura que viabilize a comunicação direta dos funcionários com a administração, com o intuito de deixá-los mais confortáveis para comunicar supostos incidentes. Além disso, a literatura indica a importância de que seja 
definido somente um porta-voz destinado a fornecer as informações sobre a crise para o público externo a fim de evitar contradições que possam abalar ainda mais a imagem da organização, e este deve estar a par de todo o processo de contenção da mesma. Caso seja necessário mais que um, a coordenação das mensagens torna-se fundamental (BALSER, FOXMAN, 2005). Ainda em relação à comunicação, Kádárová et al. (2015) enfatizam a sua importância para a resolução bem-sucedida de uma crise corporativa. Os autores lembram que, mesmo em condições normais, há a tendência de os empregados confundirem a especulação com a realidade e, se esses sinais passam despercebidos, podem se tornar problemáticos para a gestão. A quantidade de informação incontrolada, distorcida, emocionalmente motivada e a especulação pode levar à formação de distúrbios em massa e tornar-se um obstáculo na gestão racional das situações de crise.

Gladu (2003) esclarece também a importância de que a fase de recuperação de uma crise inclua um processo de aprendizagem organizacional para avaliar as ações apreendidas durante a experiência, podendo as crises ou emergências ter efeitos positivos ou negativos, tanto no processo organizacional como na imagem pública de uma organização.

Pode-se esperar que os impactos positivos e negativos gerados pela crise na administração da organização sejam refletidos nas cinco funções básicas da gestão: planejamento, organização, controle, execução e liderança. Por isso elas serão usadas como balizas para o levantamento dos impactos no estudo empírico aqui realizado.

Com base na literatura acerca do tema gestão de crises, podem ser identificados possíveis impactos positivos e negativos sobre a administração de uma organização ocasionados pela ocorrência de uma crise. Foram encontradas menções ao aprendizado do órgão e o fortalecimento da sua estrutura (BoIN et al., 2005; GLADU, 2003), como investimento na capacitação dos indivíduos, aperfeiçoamento e implantação de ferramentas que auxiliem no controle dos processos, e mudança na cultura organizacional, de uma cultura mais flexível para uma mais rígida, na qual os indivíduos passem a ter maior responsabilidade com as competências no trabalho. Quanto aos prejuízos, estão danos sobre a imagem da organização e sobre o clima organizacional (RoSA, 2003), com evidências tais como estresse, relações de trabalho instáveis, ruídos ou falhas na comunicação.

Por fim, autores internacionais como Gladu (2003), Balser e Foxman (2005) e Farazmand (2001) defendem a existência de um planejamento estratégico nas instituições, com fases distintas e claras, capaz de ser forte instrumento em momentos turbulentos, sendo que sua atuação não se restringe apenas ao momento de crise, mas refere-se também tanto ao momento que a antecede quanto ao momento pós-crise. Isso evidencia alguns dos possíveis desdobramentos 
da crise sobre a gestão. Nascimento (2007) cita três passos para a elaboração de um plano de crise: (1) analisar os procedimentos da empresa; (2) estabelecer metas; e (3) montar sua estratégia de atuação.

\section{Métodos e técnicas de pesquisa}

A pesquisa realizada teve abordagem qualitativa e natureza exploratóriodescritiva (RICHARDSON, 1999). A coleta de dados contou com pesquisa documental e com pesquisa de campo para o levantamento de dados primários. Foram realizadas entrevistas nas dependências do Ministério do Turismo em Brasília DF, entre dezembro de 2015 e janeiro de 2016, junto a sete gestores, técnicos e servidores do ministério. Para a coleta dos dados foi utilizado um roteiro de entrevista semiestruturado contendo nove questões a respeito da crise que teve surgimento com a Operação Voucher no MTur. A escolha desses respondentes se deu pelo fato de que eles estavam em exercício no órgão na época da Operação Voucher. Além disso, foi observado que tais entrevistados possuem hoje cargos de gestão no ministério, o que os qualificaria para uma obtenção de dados mais densos. ${ }^{2}$ Devido ao teor abordado neste trabalho, que poderia implicar em alguma dificuldade na obtenção de dados, e para possibilitar uma ampla verificação empírica sobre o tema, para que fosse possível chegar a essa lista final de respondentes, foi aplicada a técnica do snowball, também conhecida por bola de neve, durante a realização das entrevistas. Sendo assim, foi solicitado aos participantes que estavam na lista inicial de entrevistados que indicassem outros colaboradores do MTur para participarem da coleta, considerados por eles relevantes para agregar mais conteúdo à pesquisa.

As entrevistas duraram em média 25 minutos, com variação de 15 minutos e 23 segundos a 35 minutos e 15 segundos, e foram gravadas e transcritas ${ }^{3}$. Apenas um dos entrevistados respondeu por escrito, porque estava de férias no momento da coleta de dados. Os respondentes serão identificados com letras (E1, E2 etc.) ao longo do trabalho, mas não serão aqui associados a seus cargos específicos à época da crise ou atuais a fim de zelar pelo sigilo de suas identidades, constando neste trabalho apenas as informações que não ferem o princípio de anonimato acordado

\footnotetext{
2 Incluiu-se também a Direção de Planejamento e Gestão Estratégica, mesmo que não tenha vivenciado a crise em si e sim o período pós-crise, devido à relevância do cargo para o assunto abordado nesta pesquisa. Os demais entrevistados ingressaram no MTur entre os anos de 2005 e 2010.

${ }^{3}$ Os membros da equipe de pesquisa não faziam parte da organização estudada no momento da pesquisa. Uma das pessoas fez parte da organização em um cargo comissionado por um ano (2014-2015) e em período anterior à realização da pesquisa. Seu trabalho junto à organização colaborou para a percepção acerca da problemática de pesquisa e para o acesso aos entrevistados. A pessoa que conduziu as entrevistas nunca fez parte da organização e teve seu primeiro contato neste estudo.
} 
com os entrevistados. As entrevistas foram cessadas quando os dados já apareciam de forma redundante.

Tabela 1 - Dados dos participantes da coleta de dados

\begin{tabular}{cccccc}
\hline \multicolumn{7}{c}{ Dados dos participantes da coleta de dados } \\
\cline { 2 - 5 } Participantes & $\begin{array}{c}\text { Na época da } \\
\text { crise }\end{array}$ & $\begin{array}{c}\text { Na época da } \\
\text { realização da } \\
\text { pesquisa }\end{array}$ & $\begin{array}{c}\text { Ano de } \\
\text { ingresso } \\
\text { no MTur }\end{array}$ & $\begin{array}{c}\text { Data da } \\
\text { entrevista }\end{array}$ & $\begin{array}{c}\text { Tempo de } \\
\text { duração da } \\
\text { entrevista }\end{array}$ \\
\hline E1 & Coordenação & Assessoria & 2007 & $04 / 01 / 2016$ & Via email \\
\hline E2 & Chefia & Assessoria & 2006 & $18 / 12 / 2015$ & $00: 35: 15$ \\
\hline E3 & Técnico & Coordenação & 2008 & $22 / 12 / 2015$ & $00: 30: 17$ \\
\hline E4 & Coordenação & Coordenação & 2005 & $07 / 01 / 2016$ & $00: 34: 45$ \\
\hline E5 & $* 1$ & Direção & 2012 & $07 / 01 / 2016$ & $00: 15: 23$ \\
\hline E6 & Assessoria & Assessoria & 2010 & $13 / 01 / 2016$ & $00: 37: 17$ \\
\hline E7 & Coordenação & Coordenação & 2008 & $15 / 01 / 2016$ & $00: 23: 32$ \\
\hline
\end{tabular}

Fonte: Elaboração própria.

Para a análise de dados, foi utilizada a técnica de análise de conteúdo (Vergara, 2010), favorecendo a utilização de diferentes técnicas para tratamento do material coletado (VIEIRA; ZOUAIN, 2005). Aplicada aos estudos organizacionais, essa técnica auxilia a responder diversas questões que levam em consideração quem fala, o que fala e de que ponto de vista o faz (CORNELSEN, 2009).

Assim, o trabalho de análise foi realizado em três fases:

1. Tratamento: transcrição das entrevistas a partir das gravações.

2. Categorização: leitura das transcrições para identificação das partes mais relevantes para o trabalho em relação às categorias delimitadas conceitualmente. Nessa fase, as variáveis foram identificadas de acordo com os objetivos específicos por meio das questões utilizadas no roteiro de entrevista e as respostas dos entrevistados, como apresentado na Tabela Delimitação das Categorias para Análise dos Dados Coletados a seguir (vide Tabela 2).

3. Análise: construção de um conjunto de planilhas para compilação, análise e interpretação dos dados (Excel). A primeira planilha continha o perfil dos entrevistados; a segunda, as variáveis envolvidas nas questões e relacionadas com os objetivos específicos; a terceira compilava as conclusões individuais a respeito da resposta de cada entrevistado; a quarta contém os trechos mais importantes, com exemplos de falas a serem utilizadas na discussão dos resultados; e, por fim, a quinta planilha reuniu todas as informações para facilitar a análise rigorosa dos dados qualitativos apurados nas entrevistas. 
Tabela 2 - Delimitação das categorias para análise dos dados coletados

\begin{tabular}{|c|c|c|}
\hline Roteiro de entrevista & Objetivos específicos & Variáveis analisadas \\
\hline $\begin{array}{l}\text { 1. Na sua avaliação, a Operação } \\
\text { Voucher pode ser considerada uma } \\
\text { crise na história do Mtur? Pode } \\
\text { relatar um pouco como esta crise } \\
\text { surgiu, o que representou para o } \\
\text { órgão e como se desdobrou? }\end{array}$ & $\begin{array}{l}\text { Caracterizar a crise } \\
\text { ocorrida no Ministério } \\
\text { do Turismo em } 2011 \\
\text { (antecedentes e fases). }\end{array}$ & $\begin{array}{l}\text { Crise, órgão e } \\
\text { Operação Voucher. }\end{array}$ \\
\hline $\begin{array}{l}\text { 2. Quais foram as primeiras atitudes } \\
\text { tomadas pelo Ministério quando a } \\
\text { crise foi deflagrada? }\end{array}$ & \multirow{4}{*}{$\begin{array}{l}\text { Descrever a forma como } \\
\text { o órgão, na figura de } \\
\text { seus gestores, técnicos e } \\
\text { servidores, gerenciou a } \\
\text { crise. }\end{array}$} & $\begin{array}{l}\text { Crise e atitudes do } \\
\text { ministério. }\end{array}$ \\
\hline $\begin{array}{l}\text { 3. Havia um plano de ação de } \\
\text { contenção para crises? Alguma } \\
\text { equipe responsável para gerenciar } \\
\text { a crise? E para promover mudanças } \\
\text { após a crise? }\end{array}$ & & $\begin{array}{l}\text { Crise, plano de } \\
\text { contenção e } \\
\text { pós-crise. }\end{array}$ \\
\hline $\begin{array}{l}\text { 4. De que forma os setores mais } \\
\text { afetados lidaram com a crise? }\end{array}$ & & $\begin{array}{l}\text { Crise e setores } \\
\text { (departamentos). }\end{array}$ \\
\hline $\begin{array}{l}\text { 5. Como ficou o ambiente } \\
\text { organizacional durante e } \\
\text { após a crise? Qual era o clima } \\
\text { na organização? Quais as } \\
\text { consequências disso na gestão? }\end{array}$ & & $\begin{array}{l}\text { Crise, ambiente e } \\
\text { clima organizacional. }\end{array}$ \\
\hline $\begin{array}{l}\text { 6. Ainda hoje o ministério sofre } \\
\text { algum prejuízo decorrente desta } \\
\text { crise? Qual(is)? }\end{array}$ & \multirow{4}{*}{$\begin{array}{l}\text { Verificar os impactos } \\
\text { positivos e negativos da } \\
\text { crise sobre a gestão do } \\
\text { órgão, dando enfoque } \\
\text { às cinco funções } \\
\text { da administração: } \\
\text { planejamento, } \\
\text { organização, execução, } \\
\text { controle e liderança, bem } \\
\text { como sobre o aprendizado } \\
\text { organizacional. }\end{array}$} & $\begin{array}{l}\text { Crise e prejuízo para } \\
\text { o órgão. }\end{array}$ \\
\hline $\begin{array}{l}\text { 7. O(A) senhor(a) avalia ter havido } \\
\text { impactos positivos da crise sobre as } \\
\text { funções administrativas (planejar, } \\
\text { organizar, executar, controlar e } \\
\text { liderar)? }\end{array}$ & & $\begin{array}{l}\text { Crise, impactos } \\
\text { positivos e gestão } \\
\text { (planejar, organizar, } \\
\text { controlar, executar e } \\
\text { liderar). } \\
\end{array}$ \\
\hline $\begin{array}{l}\text { 8. E avalia algum impacto negativo } \\
\text { para estas mesmas funções? }\end{array}$ & & $\begin{array}{l}\text { Crise, impactos } \\
\text { negativos e gestão } \\
\text { (planejar, organizar, } \\
\text { controlar, executar e } \\
\text { liderar). }\end{array}$ \\
\hline $\begin{array}{l}\text { 9. Como o(a) senhor(a) via a gestão } \\
\text { do MTur antes da crise e como } \\
\text { a vê hoje? Qual o aprendizado } \\
\text { acumulado para o órgão? }\end{array}$ & & Crise e gestão. \\
\hline
\end{tabular}




\section{Resultados e discussão}

\section{Conhecendo o caso: a Operação Voucher}

A Operação Voucher consistiu em uma operação da Polícia Federal que, em conjunto com o Tribunal de Contas da União e com o Ministério Público Federal, tinha como objetivo combater o desvio de recursos públicos destinados ao Ministério do Turismo por meio de emendas parlamentares ao Orçamento da União (BRASIL, 2011).

Tratava-se, segundo o inquérito, do contrato firmado pelo Ministério do Turismo com o Instituto Brasileiro de Desenvolvimento de Infraestrutura Sustentável (Ibrasi), entidade de fachada que foi pivô do esquema investigado. O convênio, no valor total de R\$ 5 milhões, foi assinado para "Implantação de processos participativos para Fortalecimento da Cadeia Produtiva de Turismo do Estado do Amapá", mas nunca existiu de fato (ESTADÃo, 2011). O Ibrasi firmou três convênios no valor total de R\$17 milhões com o Ministério do Turismo desde 2009. A polícia calculava um desvio de mais de R\$10 milhões, o maior percentual de desvio já apontado numa operação da PF até aquele momento (O GLOBO, 2011).

A Justiça expediu mandados de prisão de 38 pessoas, em Brasília, São Paulo, Macapá e Curitiba (G1, 2011). Entre os envolvidos estavam: o Secretário Executivo do Ministério do Turismo, o empresário apontado como dono de uma das empresas subcontratadas pela ONG Ibrasi, o Secretário de Programas de Desenvolvimento do Turismo, uma deputada do Amapá, além de servidores do ministério, políticos e empresários ligados à Ibrasi. Essa é a crise sobre a qual este trabalho tratará, do ponto de vista de seu gerenciamento e dos impactos que se desdobraram sobre a gestão do órgão, considerando os objetivos geral e específicos anteriormente expostos.

\section{Caracterização da crise do MTur: antecedentes, desdobramentos e suas fases}

Houve unanimidade entre os entrevistados ao considerarem a Operação Voucher uma crise na história do MTur. Na compreensão deles, antes de passar por essa experiência, o Ministério do Turismo mantinha uma flexibilidade excessiva na execução dos seus serviços. Ficou evidente que a operação trouxe à tona fragilidades, principalmente com relação ao controle dos processos. Os entrevistados indicam que faltava conhecimento acerca da Legislação e dos processos formais do setor público entre os servidores. Muitos justificaram esse despreparo pelo fato de o Ministério ser um órgão novo, criado em 2003. Entre os problemas mencionados pelos entrevistados nessa etapa da pesquisa, foram ressaltados: 
- Falhas na comunicação interna:

Num primeiro momento ninguém entendeu o que estava acontecendo. Lembro de acordar no dia da operação com a ligação de um colega de um Estado me perguntando se estava tudo bem comigo. Chegando no ministério, encontramos uma chuva de informações desencontradas. Não sabíamos quantas pessoas haviam sido presas, quem tinha sido preso ou mesmo o motivo de fato das prisões. Não me recordo de nenhuma ação proativa do ministério no período, somente ações reativas, especialmente por parte do Ministro" (E1).

Então as pessoas no ministério se informavam ou viam fontes externas ou viam é... os colegas de trabalho, né (sic)?, ouviam rádio corredor. Então, isso (a comunicação interna) no momento de crise é uma das principais é... ferramentas para... para conter a crise, para... para... é... para limitar a crise, para delimitar a crise é a informação adequada, né (sic)? [E3]

É porque muitos relataram que não tiveram um posicionamento mesmo do gestor, do ministro, que ficou todo mundo meio perdido (...). Foi do tipo assim: "Vamos punir, vamos...", sem nem saber se tinha alguma coisa a ver com o negócio... [E7].

- Falta de padronização dos processos:

Então, assim, no primeiro ponto é que se viu que todos os nossos processos ali estavam muito frágeis... existem as leis do direito administrativo, existem as regras para liberação de convênio, existem os trâmites legais, e muitas vezes eles não foram cumpridos e muitas vezes por despreparo do servidor, por despreparo do gestor também, porque muitas vezes... eu, no meu ponto de vista, não foi por má fé [E2].

Era como se a gente repassasse o recurso para ela e ela pegasse esse recurso e repassasse para terceiros para fazer todo convênio... e isso não poderia ter acontecido [E4].

- Falta de liderança:

Não tenho nem nada a dizer... eu não acho que... que foram bons líderes não. Não acho que na época teve um processo de liderança, entendeu? De assumir a gestão interna, de... de... sabe? De gestão de crise, de chamar os servidores, de acolher, acho que não teve em nenhum momento isso. Eu acho que inclusive foi ao contrário, sabe? [E2]

Eu acho que na função liderar não mudou... eu não observo que mudou significativamente após a crise, porém eu acho que exige é... é... o fato de ter acontecido a crise exige é... um... uma postura diferente dos gestores [E3].

Depois da Operação Voucher, a gente teve uma série de casos de servidores que se recusavam a fazer o trabalho para o qual estavam contratados [E6]. 
Portanto, é possível compreender o porquê de a Operação Voucher ter sido para o MTur uma crise de proporções tão grandes, como percebido através das respostas dos entrevistados. Os relatos demonstram que a liderança não exerceu um bom diálogo com os servidores e funcionários, dando abertura para atitudes improvisadas, como a paralisia do trabalho. As respostas indicaram que não havia uma equipe preparada para crise, com pessoas dotadas de tal conhecimento. Isso ocorreu às pressas com a deflagração da crise no ministério, sem uma atuação sistematizada ou planejamento para gerenciamento da crise.

\section{Gerenciando a crise no MTur: atitudes dos gestores e setores, planos de contenção, pós-crise e clima organizacional}

Considerando a gestão de crises ser dividida em quatro fases - mitigação, preparação, resposta e recuperação (GLADU, 2003) - apesar de o Ministério do Turismo não ter seguido um planejamento estratégico para a resolução da crise, é possível observar algumas características dessas fases no desenvolvimento da crise em estudo.

Quanto à primeira fase, mitigação, em que as medidas são tomadas para reduzir as consequências de uma crise ou emergência, o ministério não havia passado por experiências similares anteriores, nem possuía um plano de contenção de crises, como afirmado pela maioria dos entrevistados, nem uma equipe responsável pelo gerenciamento de crises. Observa-se aqui que as medidas tomadas com o propósito de reduzir as consequências da Operação Voucher na organização foram a criação de um manual de convênios, a fim de padronizar os processos e evitar que os mesmos erros se repetissem, assim como a criação dos programas de controle dos processos, como o Sistema de Acompanhamento dos Contratos de Repasse (Siacor), por exemplo.

Na segunda fase, a preparação, na qual a organização deve preparar-se para a crise efetiva ou para uma resposta de emergência, não foi observada nenhuma similaridade com o gerenciamento da crise ocasionada pela Operação Voucher no MTur.

A terceira fase, voltada para respostas, que deve fornecer as medidas tomadas para lidar com as consequências de uma crise ou uma emergência, foi a mais perceptível no caso do Ministério do Turismo, apesar de o clima de insegurança no ministério ter permanecido presente e os servidores e funcionários ainda não possuírem o total conhecimento do fato. Porém, podemos considerar como pertencentes a essa fase a suspensão dos convênios e a paralisia dos processos, além da formação de uma equipe para resolução da crise, para a qual um dos objetivos era nomear porta- 
vozes oficiais encarregados de prestar os esclarecimentos necessários à imprensa sobre o fato ocorrido no ministério, como relatado pelo E6 em resposta à questão descrita a seguir.

Por fim, a quarta e última fase, a recuperação, responsável por medidas tomadas no respaldo de uma crise, como a declaração do seu fim, voltando às operações normais, foi a mais discreta de todas. De fato, a crise foi superada. No entanto, a relação com os parceiros ficou estremecida, os servidores e funcionários ainda não têm total segurança quanto aos processos realizados, ainda temem assinar documentos e afirmam não terem tido nenhum apoio por parte da organização. Apesar disso, segundo os relatos, o MTur tirou lições para melhoria dos seus processos a partir dessa experiência, como poderá ser visto mais adiante neste trabalho.

Essas evidências descritas nas fases do quadro de gestão de crises referente ao MTur revelam que a gerência da crise que se instaurou no ministério não ocorreu da forma como sugere a literatura, apesar de demonstrar alguns pontos em comum com a descrição de uma gerência de crise bem-sucedida (FARAZMAND, 2001). Essa relação é descrita a seguir.

(1) Um sentindo de urgência à questão:

Na época da Operação Voucher, o MTur concentrou todo o seu foco sobre a crise.

E... e nesse meio tempo, durante a Operação Voucher, a gente ficou aí é... por um período realmente paralisado como eu falei já, com o foco todo concentrado nas... na... na gestão da crise, em estancar aquela crise que estava afetando todo o... todo o ministério [E6].

(2) Pensar de forma criativa e estratégica para resolver a crise:

Talvez não se possa considerar que a paralisia dos processos e a suspensão de todos os convênios tenham sido formas estratégicas e criativas para solucionar a crise. Essas medidas, segundo os entrevistados, foram tomadas para frear os processos a fim de analisar a situação. Alguns deles alegaram que há a possibilidade de que o MTur, no momento da crise, tenha agido por impulso, como se não tivesse outra decisão a ser tomada.

(3) Tomar ações ousadas, agindo com coragem e sinceridade:

A realização de um evento voltado para os servidores da casa no Teatro Nacional, com a presença do novo Ministro e do novo Secretário Executivo, com o objetivo de motivar os servidores novamente para o seu trabalho, pode ser considerada como uma dessas ações. Esse fato foi relatado pelo E6, mas não foi reconhecido pelos outros entrevistados. 
(4) Romper com a cultura organizacional de autoproteção, assumindo riscos e ações que possam produzir melhores soluções em que não haveria perdedores significativos:

Nesse caso, o que aconteceu com o MTur foi o inverso, de acordo com os entrevistados. Após a crise, foi sendo construída aos poucos uma cultura de autoproteção, capaz de dar mais segurança aos processos, através de uma padronização e uma execução com um acompanhamento mais rígido.

(5) Manutenção de uma presença contínua na situação que muda rapidamente com o desenrolar dos eventos dramáticos:

Mesmo após a crise que marcou a história do MTur, apesar de todos os aprimoramentos feitos na gestão para sanar as falhas expostas com a crise, todos os entrevistados, exceto o E6, alegaram que o ministério não possui um plano de contenção para crises, nem uma equipe especializada. Logo, pode-se concluir que essa manutenção descrita pelo autor não vem sendo realizada.

Além disso, todos os participantes alegaram que o ambiente e clima organizacional após a Operação Voucher eram péssimos, citando como principais consequências a insegurança nos procedimentos internos e a inoperância dos órgãos. Muitos funcionários ficaram traumatizados e sofrem com isso até hoje. Para os que estavam envolvidos, principalmente devido à exposição da imagem, as consequências envolvem danos psicológicos relatados. Para os que permaneceram no órgão sem maiores problemas, o medo ainda prevalece no clima organizacional.

Então o que demorava uma semana para fazer, começou a demorar um mês, seis meses e as pessoas ficaram com bastante desconfiança; o clima ficou ainda muito ruim [E5].

Quem viveu ali dentro daquele departamento tem trauma; trauma de buscar psicólogo e tudo mais, porque foi uma ação que foi televisionada o tempo inteiro, as pessoas foram expostas, os rostos delas foram expostos, os nomes foram expostos [E2].

(...) o clima organizacional foi bastante afetado a ponto de paralisar o ministério. Por algumas semanas, o ministério, as áreas fim do ministério, elas ficaram realmente paralisadas e toda a energia do ministério ficou concentrada em estancar aquela crise (...) [E6].

É de se entender porque o dano à imagem é uma preocupação presente em situações de crise. Como mencionado no referencial, de acordo com Rosa (2003), as crises de imagem, diferentes de todas as outras que podem atingir líderes ou organizações, sendo potencialmente mais devastadora do que as "crises comuns", 
levam com que a resposta à imprensa seja uma das primeiras atitudes a ser tomadas por um órgão diante da crise.

A forma com a qual o caso repercutiu na imprensa e a exposição da imagem de alguns servidores e funcionários do MTur contribuíram ainda mais para o agravamento desse quadro. Como os entrevistados relataram, o MTur não se posicionou adequadamente frente aos seus servidores e funcionários, assim como não demonstrou nenhum apoio aos mesmos, sendo compreensível o caráter negativo atribuído ao clima organizacional da época.

\section{Impactos positivos e negativos da crise sobre a administração do MTur e aprendizado organizacional}

De acordo com as respostas dos entrevistados, pode-se dizer que foram observados nas falas pontos positivos nas seguintes funções administrativas:

1. Planejar

Hoje a gente tem processo de planejamento todo sistematizado, tem... hoje tem metas por área de... de execução, tem um planejamento estratégico no sistema, tem reuniões que são trimestrais onde a gente apresenta tudo, as... as... as áreas técnicas apresentam pro Gabinete do Ministro todas as suas metas, tem metas por servidor. Então hoje o servidor tem a sua produção, isso impacta no salário do servidor, na carreira dele. Então hoje tem um planejamento interno, tem um planejamento externo, que é o Plano Nacional de Turismo, né (sic)? Então a forma de atuação do Ministério do Turismo mudou, consideravelmente, após a Operação Voucher [E2].

2. Organizar

(...) Essa ferramenta permitiu que a gente perdesse menos prazo, que a gente tivesse uma relação mais profissional com os órgãos de controle [E6].

(...) Melhorou, inclusive, a forma do ministério alocar recurso, porque, como era muito fácil celebrar convênio, e não tinha um cri... processo seletivo para selecionar as organizações que celebravam convênio, não tinha muito critério na hora de se acompanhar a execução, então se acaba por pulverizar o dinheiro público com uma série de projetos que não tinham o resultado esperado [E3].

\section{Controlar}

O ministério saiu na frente, criou uma ferramenta chamada Siacor, que é Sistema de Acompanhamento dos Contratos de Repasse, que permitia a visualização em um painel de todas as obras executadas com dinheiro do 
ministério em todos os estados. É... isso permitiu um diálogo mais transparente, mais objetivo com o Congresso, já que grande parte do recurso do ministério vem de emendas parlamentares (...). Isso foi um ganho substancial para o ministério, para a gestão do ministério, assim, que permitiu uma tomada de decisão mais correta, mais objetiva, menos sujeita a... interferências políticas. É... do ponto de vista negativo, né (sic)? [E6]

A gente já ganhou no concurso de transparência da CGU também, prêmios por ser transparente e mostrar à sociedade o que a gente vem fazendo [E5].

4. Liderar

O Secretário Executivo [nome omitido] e o [nome omitido], que era o Diretor Estratégico aqui, eles folhearam a crise e conseguiram dar um salto de qualidade... A gente deve muito isso a eles [E5].

A liderança, a gente contou com... com... com duas pessoas que foram fundamentais nesse processo: o próprio Ministro, que recém-chegado tomou essa decisão de fazer o freio de arrumação, dar o freio, freada de arrumação mesmo com todos os questionamentos e com toda pressão no sentido contrário, e o Secretário Executivo, que é um líder nato, digamos assim. (...) Por meio dessas duas lideranças à época, os servidores conseguiram ver que existia ali uma luz no fim do túnel e que dava para acreditar naquele discurso (...) [E6].

Porém, é válido ressaltar que os participantes E2 e E3 não viram pontos positivos na função liderar, e o E7, além de ter relatado alguns pontos positivos, acrescenta pontos negativos a essa função, como descrito a seguir.

Com relação à função executar, não foram citados com clareza pelos participantes pontos positivos significativos. Porém, a partir da análise das falas de alguns entrevistados, podem ser observadas melhorias, como um maior monitoramento dos processos (um acompanhamento mais rigoroso), assim como o aumento da responsabilidade por parte dos servidores e funcionários durante a execução do serviço prestado.

Por outro lado, quanto aos impactos negativos para essas mesmas funções mencionadas acima, de acordo com os participantes E3, E5 e E6, não houve impactos negativos sobre as funções administrativas. Já os participantes E1, E2 e E4 deixaram transparecer um impacto negativo na função executar. O E1 questionou o aumento da burocracia ${ }^{4}$ no MTur após a crise. Já o E2 afirmou que os gestores

\footnotetext{
${ }^{4} \mathrm{O}$ entrevistado mencionou a palavra burocracia de acordo com o sentido ligado ao senso comum. Porém, na administração, a palavra burocracia remete ao tipo de dominação legal de Max Weber, descrito em sua obra Economia e Sociedade (1921 [1999]), capítulo III. O autor descreve que o tipo mais puro de administração legal é aquele que se exerce por meio de um quadro administrativo burocrático.
} 
são menos proativos. O órgão passou a inovar menos, a execução dos processos tornou-se mais lenta, e assim a produtividade ficou um pouco mais baixa, com processos mais engessados, sem um trabalho ativo para melhoramento do clima organizacional. O E4 criticou o retrabalho. Além disso, as relações com as entidades que prestavam serviços para o ministério ficaram estremecidas, pois algumas delas realizaram o trabalho pelo qual receberam e estão tendo que devolver o recurso por falta de comprovação. Como se formou uma nova equipe no Departamento de Qualificação, devido ao fim, pela alta gestão, da equipe anterior - o que, segundo o E7, aconteceu sem nenhum diálogo, sem o consentimento dos indivíduos que formavam a equipe extinta -, essa nova equipe não tinha o embasamento necessário para acompanhamento do caso e era ela a responsável pelas devidas cobranças desde então.

Naquela época lá, o orçamento era quase a mesma coisa e a gente conseguia fazer muito mais [E2].

É uma coisa que não tem fim, porque a gente finaliza uma análise e fica essa coisa de ficar (sic) eles pedindo reconsideração; aí a gente finaliza; aí daqui a pouco, muda o ministro, muda o secretário, alguém mais importante... Como eles são importantes, né (sic)... São entidades representativas, eles acabam recorrendo a essas pessoas. Aí essas pessoas acabam, para não desagradar a entidade e não dizer não, aí acaba voltando para a gente analisar... [E4].

Apesar de ter respondido que os gestores, após a crise no MTur, passaram a buscar o aprimoramento do controle dos processos e a tentar transmitir essa segurança aos seus subordinados, o E7 acreditou ter havido impacto negativo na função liderar. Ele questionou a atitude da alta gestão no momento de crise, relatando que não houve amparo por parte do ministério com relação aos servidores, e acrescentou que, após a Operação Voucher, os servidores e funcionários passaram a desacreditar em seus líderes, mantendo o receio de assinar os documentos, de fazer o que a eles é delegado.

Eu acho que as pessoas confiam menos agora nos líderes, eu acho que não foi positivo [E7].

Contudo, apesar de alguns entrevistados terem mencionado a liderança como uma das funções dotadas de aspectos positivos, o que prevaleceu na visão deles foram aspectos negativos para essa função. Embora tenha sido relatado que a evolução do MTur no pós-crise se deu devido à liderança que assumiu o ministério, ponto mais presente nos relatos do E6, muitos criticaram os líderes por desamparo e descontrole diante do dano causado ao clima organizacional. 
Com relação à literatura, é válido destacar que Balser e Foxman (2005) ressaltam a importância de o gestor conhecer bem os seus funcionários. Além disso, Gladu (2003), ao descrever um bom gestor, afirma que o mesmo deve ser perceptivo, alguém que sabe manter a calma sob pressão, entre outras qualidades. Essas duas características foram as que mais fizeram falta no perfil dos gestores na crise do MTur.

De modo geral, fica claro que o MTur passou a investir mais em transparência e no controle dos processos, além de aprender que, por se tratar de recurso público, deve-se fazer apenas aquilo que lhe compete fazer, o que está nas leis e regras do serviço público. Com isso, o órgão tornou-se mais responsável, assim como seus funcionários e servidores passaram a dar mais atenção às padronizações do serviço público.

Após esta discussão dos resultados, é válido ressaltar o conceito de gestão de crises definido por Balser e Foxman (2005): uma gestão e coordenação das respostas da instituição a um incidente que ameaça prejudicar, ou tem prejudicado, os funcionários da instituição, estruturas, capacidade de operar, objetos de valor e a reputação, o que, na maioria das vezes, significa tomar decisões sobre o futuro da instituição sob grande carga de estresse e com a falta de peças-chave da informação.

Esse conceito se adequa ao caso em estudo, visto a proporção da crise instaurada no MTur. O clima organizacional e a imagem do ministério foram fortemente abalados, e os custos necessários para que o órgão voltasse a cumprir com as suas demandas sem a ocorrência dos mesmos erros que levaram ao surgimento da crise ocasionada pela Operação Voucher foram altos. Além disso, a grande carga de estresse e a falta de peças-chave da informação, mencionadas pelos autores, compõem o cenário no qual a crise se deu. A Tabela 3 resume os impactos positivos e negativos sobre as funções administrativas do MTur após a crise em estudo. 
Tabela 3 - Impactos positivos e negativos sobre a gestão do MTur

\begin{tabular}{|c|c|c|c|c|c|}
\hline \multicolumn{6}{|c|}{ Funções administrativas } \\
\hline Impactos & Planejar & Organizar & Controlar & Executar & Liderar \\
\hline Participantes & $\begin{array}{l}\text { E1, E2, E4, } \\
\text { E6 }\end{array}$ & $\begin{array}{l}\text { E1, E2, E3, } \\
\text { E4, E6, E7 }\end{array}$ & $\begin{array}{l}\text { E1, E2, E3, } \\
\text { E5, E6 }\end{array}$ & $\begin{array}{l}\text { Os } \\
\text { entrevistados } \\
\text { não citaram, } \\
\text { de forma } \\
\text { direta, } \\
\text { impactos } \\
\text { positivos sobre } \\
\text { esta função }\end{array}$ & E5, E6, E7 \\
\hline Positivos & $\begin{array}{l}\text { O planeja- } \\
\text { mento do } \\
\text { órgão passou } \\
\text { a ser todo } \\
\text { sistematiza- } \\
\text { do. Foram } \\
\text { estabelecidas } \\
\text { metas por } \\
\text { área e para } \\
\text { os servidores. } \\
\text { Além disso, } \\
\text { passaram a } \\
\text { ser realizadas } \\
\text { reuniões } \\
\text { trimestrais } \\
\text { onde as áreas } \\
\text { técnicas apre- } \\
\text { sentam para } \\
\text { o gabinete } \\
\text { do minis- } \\
\text { tro os seus } \\
\text { resultados. }\end{array}$ & $\begin{array}{l}\text { Foram criados } \\
\text { programas } \\
\text { de controle } \\
\text { capazes de } \\
\text { orientar o } \\
\text { MTur quanto } \\
\text { ao repasse } \\
\text { e melhor } \\
\text { alocação dos } \\
\text { recursos, } \\
\text { assim quanto } \\
\text { aos prazos } \\
\text { que devem } \\
\text { ser respei- } \\
\text { tados para } \\
\text { prestação de } \\
\text { contas com } \\
\text { os órgãos de } \\
\text { controladoria } \\
\text { exernos. }\end{array}$ & $\begin{array}{l}\text { Foram } \\
\text { criados pro- } \\
\text { gramas que } \\
\text { garantem } \\
\text { ao Mtur a } \\
\text { segurança } \\
\text { e transpa- } \\
\text { rência dos } \\
\text { processos, } \\
\text { como o } \\
\text { SIACOR, } \\
\text { citado pela } \\
\text { maioria dos } \\
\text { entrevis- } \\
\text { tados, por } \\
\text { exemplo. }\end{array}$ & $\begin{array}{l}\text { Passou-se a } \\
\text { investir em um } \\
\text { maior moni- } \\
\text { toramento da } \\
\text { execução no } \\
\text { MTur, assim } \\
\text { como o próprio } \\
\text { órgão, funcioná- } \\
\text { rios e servidores } \\
\text { passaram a ser } \\
\text { mais responsá- } \\
\text { veis durante a } \\
\text { execução dos } \\
\text { serviços. }\end{array}$ & $\begin{array}{l}\text { Os líderes } \\
\text { que assumi- } \\
\text { ram o MTur } \\
\text { após defla- } \\
\text { gração da } \\
\text { crise fizeram } \\
\text { ascender no } \\
\text { ministério } \\
\text { lideranças já } \\
\text { existentes na } \\
\text { estrutura or- } \\
\text { ganizacional. } \\
\text { Os gestores } \\
\text { também } \\
\text { passaram } \\
\text { a buscar o } \\
\text { aprimora- } \\
\text { mento do } \\
\text { controle dos } \\
\text { processos e } \\
\text { a transmitir } \\
\text { maior segu- } \\
\text { rança aos } \\
\text { funcionários } \\
\text { e servidores, } \\
\text { fazendo des- } \\
\text { sa preocu- } \\
\text { pação parte } \\
\text { da rotina de } \\
\text { trabalho no } \\
\text { Mtur }\end{array}$ \\
\hline
\end{tabular}




\begin{tabular}{|c|c|c|c|}
\hline Participantes & $\begin{array}{l}\text { Para os entrevistados, não houve } \\
\text { impactos negativos sobre estas funções }\end{array}$ & E1, E2, E4 & $\begin{array}{l}\text { E1, E2, E3, } \\
\text { E4, E7 }\end{array}$ \\
\hline Negativos & - & $\begin{array}{l}\text { Houve um } \\
\text { aumento da } \\
\text { burocracia nos } \\
\text { processos, os } \\
\text { gestores são me- } \\
\text { nos proativos e o } \\
\text { retrabalho ainda } \\
\text { demanda muito } \\
\text { tempo do órgão. } \\
\text { Os processos } \\
\text { tornaram-se } \\
\text { mais lentos e a } \\
\text { produtividade } \\
\text { do MTur caiu } \\
\text { consideravel- } \\
\text { mente com } \\
\text { relação à época } \\
\text { que antecede a } \\
\text { crise. }\end{array}$ & $\begin{array}{l}\text { No período } \\
\text { da coleta de } \\
\text { dados, após } \\
\text { pouco mais } \\
\text { de } 4 \text { anos da } \\
\text { ocorrência } \\
\text { da crise, os } \\
\text { funcionários } \\
\text { e servidores } \\
\text { ainda des- } \\
\text { confiam dos } \\
\text { seus líderes } \\
\text { e temem } \\
\text { realizar al- } \\
\text { guns serviços } \\
\text { delegados } \\
\text { por eles, } \\
\text { como o fato } \\
\text { de recusarem } \\
\text { assinar de- } \\
\text { terminados } \\
\text { processos, } \\
\text { por exemplo. }\end{array}$ \\
\hline
\end{tabular}

Fonte: Elaboração própria.

\section{Considerações finais}

$\mathrm{O}$ artigo teve como objetivo analisar os impactos positivos e negativos da crise ocasionada pela Operação Voucher sobre a gestão do Ministério do Turismo no ano de 2011. Assim, o trabalho caracterizou a crise em relação a seus antecedentes e fases; descreveu a forma como foi gerenciada por seus gestores, técnicos e servidores; e verificou os impactos positivos e negativos da crise sobre a gestão do órgão, dando enfoque às cinco funções da administração: planejamento, organização, execução, controle e liderança, bem como sobre o aprendizado organizacional.

Foi possível constatar que, de fato, sob o olhar dos entrevistados, a Operação Voucher foi uma crise na história do Ministério do Turismo, que surgiu de forma inesperada, tendo a sua deflagração desestabilizado a estrutura do órgão. Os informantes indicaram que o MTur trabalhava com flexibilidade, que por vezes era excessiva, em suas ações. Com a crise, foi possível visualizar os erros que estavam sendo cometidos desde o início da criação do órgão e em várias linhas da hierarquia. 
Com a crise, fragilidades administrativas foram expostas e, com isso, puderam ser estudadas e tomadas as atitudes necessárias para as devidas correções.

Foi relatado nas falas que houve um diálogo insuficiente entre a alta gestão e as demais áreas do MTur, levando os servidores a se sentirem desamparados, sem um posicionamento claro dos seus superiores. É válido ressaltar que a liderança assume papel fundamental na gestão da organização em momentos de crise frente aos novos desafios para manutenção da moral da equipe, fator que não foi percebido por quem participou da crise do MTur.

Os resultados também indicam que não foi dada a devida atenção à comunicação interna. Os funcionários e servidores não tinham a informação da fonte primária, baseavam-se pelo que ouviam da imprensa e ruídos de dentro do órgão, dando abertura para atitudes prejudiciais, como a recusa à execução das suas responsabilidades. Sobre esse ponto, é importante ressaltar a ênfase dada por Kárdárová et al. (2015) à importância da comunicação, afirmando que ela é crucial para a resolução bem-sucedida de uma crise corporativa. Os autores mencionam que, mesmo em condições normais, há a tendência de os empregados confundirem a especulação com a realidade e, se esses sinais passam despercebidos, podem se tornar problemáticos para a gestão, o que foi evidenciado no caso estudado.

O clima e ambiente organizacional foram prejudicados e demonstram-se fragilizados até hoje. Os processos passaram a ser vistos com receio e insegurança. A crise evidenciou a falha em adotar procedimentos padrão, dentro das regras da administração pública, para a realização das suas ações. Além disso, a imagem do ministério e das pessoas diretamente envolvidas na Operação Voucher foi comprometida.

O MTur não tinha um plano de contenção para crises, como alegado pela maioria dos entrevistados, e não o possui até hoje, fato também afirmado pela maioria dos participantes da coleta de dados. Não existe no órgão uma equipe especializada para gerir crises, assim como recomenda a literatura internacional. Em relação às fases de uma crise: mitigação, preparação, resposta e recuperação (GLADU, 2003), foi possível perceber a presença e distinção dessas fases na crise ocorrida no MTur, ainda que nenhum entrevistado tenha feito menção a elas diretamente.

Por fim, os entrevistados revelam que a reputação do órgão foi prejudicada pelo caráter da crise em estudo. Houve também perdas de produtividade, e o clima organizacional ainda é instável em decorrência da crise analisada, sendo estes os principais prejuízos citados. Por outro lado, os resultados permitiram constatar que as crises são capazes de influenciar a gestão de um órgão do setor público em várias formas. Entre essas formas, de acordo com as funções administrativas, foram constatadas: na função planejar, a implantação de um planejamento sistematizado; 
na função organizar, a criação de programas de controle capazes de orientar o MTur quanto ao repasse e melhor alocação dos recursos, bem como quanto aos prazos a serem respeitados; na função controlar, a criação de programas que garantam ao MTur a segurança e transparência dos processos, como o Siacor; na função executar, o investimento em um maior monitoramento da execução no MTur; e na função liderar, o fato de ascenderem no ministério lideranças já existentes na estrutura organizacional.

Apesar de essas novas medidas terem originado uma cultura organizacional de aprimoramento de gestão no Ministério do Turismo, também foram observados pontos negativos na gestão. Quanto à função executar, devido ao aumento da burocracia nos processos, à queda de proatividade dos gestores e ao retrabalho que ainda demanda muito tempo do órgão, os processos tornaram-se mais lentos, resultando em uma considerável queda na produtividade do MTur com relação à época que antecede a crise. Já quanto a função liderar, mesmo após mais de quatro anos do acontecimento da crise, os funcionários e servidores ainda possuem dificuldade em confiar nos seus líderes e temem realizar alguns serviços delegados por eles, como quando, por exemplo, se recusam a assinar determinados processos. Além disso, alguns entrevistados destacaram o aumento da rotatividade no órgão, descrevendo-a como alta e prejudicial para o bom desempenho do MTur, apontando, como forte influenciador desse fato, o prejuízo à imagem do ministério decorrente dessa crise.

Este trabalho lidou com duas limitações: primeiro, a literatura nacional demonstrou pouca abordagem da temática, e, em sua maioria, voltada para o campo da Comunicação Social. Isso dificultou um aprofundamento acerca do problema dentro do campo da Administração, sendo fundamental recorrer à literatura internacional; e, segundo, a coleta de dados coincidiu com o período de recesso das organizações, o que impediu a participação de algumas pessoas que poderiam contribuir para o resultado final, pois o número de entrevistados poderia ser ampliado e os resultados obteriam um nível maior de comprovação. Assim, diante do momento de crise vivenciado pelo país atualmente, propõe-se que o tema aqui apresentado seja alvo de futuros estudos mais aprofundados, capazes de auxiliar no bom funcionamento dos órgãos públicos brasileiros e em uma melhor tomada de decisões por parte da administração pública.

\section{Referências bibliográficas}

BALSER, B. B.; FoXMAN, A. H. H. Protecting Your Jewish Institution: Security Strategies For Today's Dangerous World. United States of America: AntiDefamation League, 2005. 138 pp. 
BoIN, A. et al. The politics crisis management. Inglaterra: Cambridge, 2005.

BoIN, A. Managing crises in the twenty-first century. International Studies Review, v. 6, p. 165-194, 2004.

BRASIL (2015). Ministério do Turismo. Regimento Interno. Brasília, 2015. Disponível em: <http://www.turismo.gov.br/legislacao/?p=903>. Acesso em: 25 nov. 2015.

BRASIL. Polícia Federal. Divisão de Comunicação Social. PF deflagra a Operação Voucher. Disponível em: <http://www.pf.gov.br/agencia/noticias/2013/08/pfdeflagra-a-operacao-voucher>. Acesso em: 02 dez. 2015.

BRESSER, L. C. Da administração pública burocrática à gerencial. Revista do Serviço Público, ano 47, v. 121, n. 1, p. 7-40, jan-abr. 1996.

CARVALHO, P. M. V. Fatores que influenciam a resiliência dos gestores em tempos de crise: o caso do pequeno comércio em Portugal. Portugal: Universidade do Porto, 2014. Dissertação (Mestrado em Gestão de Serviços) - Universidade do Porto, Portugal.

CARVALHO, J. DE. Número 2 do turismo orientava empresário a ludibriar ministério. O Globo, Rio de Janeiro, 11 ago. 2011. Política. Disponível em: < https://www2. senado.leg.br/bdsf/bitstream/handle/id/428156/noticia.htm ?sequence=1>. Acesso em: 19 nov. 2015.

COHEN, E.; NEAL, M. Coinciding crises and tourism in contemporary Thailand. Current Issues in Tourism, v. 13, n. 5, p. 455-475, 2010.

Colon, LeAndro. Projeto de interesse de Sarney levou R\$ 3 milhões. Política. $O$ Estado de São Paulo, São Paulo, 12 ago. 2011. Política. Disponível em: <http:// politica.estadao.com.br/noticias/geral,projeto-do-turismo-de-interesse-de-sarneylevou-r-3-milhoes,757451>. Acesso em: 29 out. 2015.

CORLEY, K. G.; GIOIA, D. A. Identity ambiguity and change in the wake of a corporate spin-off. Administrative Science Quarterly, v. 49, n. 2, p. 173-208, 2004.

CORNELSEN, E. L. Análise do discurso no âmbito dos estudos organizacionais: uma abrodagem teórica. In: CARRIERI, A. P. et al. (Orgs.). Análise do discurso em estudos organizacionais. Curitiba: Juruá, 2009.

ENTENDA a Operação Voucher, da PF, que prendeu o número 2 do Turismo. Objetivo da operação é conter suposto desvio de verbas do ministério. Justiça expediu 38 mandados de prisão; fraude seria de quase R\$ 3 mi. G1, Brasília, 09 ago. 2011. Política. Disponível em: <http://g1.globo.com/politica/noticia/2011/08/entendaoperacaovoucher-da-pf-que-prendeu-o-numero-2-do-turismo.html>. Acesso em: 25 nov. 2015.

FARAZMAND, A. Handbook of crisis and emergency management. London: CRC Press, 2001.

FELLET, JoÃo. Um ano depois, qual o saldo dos protestos de junho de 2013? BBC Brasil, Brasília, 13 jun. 2014. Notícias. Disponível em: <http://www.bbc.com/ portuguese/noticias/2014/06/140612_saldo_protestos_junho_jf_kb>. Acesso em: 29 nov. 2015. 
GLADU, A. Crisis and emergency management: a guide for managers of the public service of Canada. Canadá: Canadian Centre for Management Development, 2003. Disponível em: < http://publications.gc.ca/site/archivee-archived.html?url=http:// publications.gc.ca/Collection/SC94-101-2003E.pdf>. Acesso em: 25 nov. 2015.

HALL, C. M. Crisis events in tourism: subjects of crisis in tourism. Current Issues in Tourism, v. 13, n. 5, p. 401-417, 2010.

JóHANNESSON, G. T.; HUIJBENS, E. H. Tourism in times of crisis: exploring the discourse of tourism development in Iceland. Current Issues in Tourism, v. 13, n. 5, p. 419-434, 2010.

KÁDÁRovÁ, J. et al. Strategy map for the crisis communication. Procedia Economics and Finance, v. 23, p. 1119-1124, 2015.

KRUGMAN, P. (Org.). A crise de 2008 e a economia da depressão. Revista de Economia Política, Rio de Janeiro, 30 (1), p . 180-182, 2010.

LI, S.; BLAKE, A.; COOPER, C. China's tourism in a global financial crisis: a computable general equilibrium approach. Current Issues in Tourism, v. 13, n. 5, p. 435-453, 2010.

LOURENÇO, M. R.; MARCHIORI, M. R. A Comunicação de Risco como Fator Essencial no Processo de Gestão de Crises. In. XII CONGRESSO DE CIÊNCIAS DA COMUNICAÇÃO NA REGIÃO SUL, Londrina - PR, 2011. 14 pp.

Maximiano, A. C. A. Organizações e administração. In: Maximiano, A. C. A. Introdução à Administração. 7. ed. ver. e ampl., 2a reimpr. São Paulo: Atlas, 2008. Cap. 1.

MENDES, António M. M. Subsídios para uma teoria das crises políticas. In: Congresso DA SOCIEDAde PortugueSA De CIÊnCIAS DA COMUnICAÇÃo, 4., 2005, Portugal. Livro de Actas... Portugal: Sopcom, 2005. p. 765-774.

MOORE, W. R. The impact of climate change on Caribbean tourism demand. Current Issues in Tourism, v.. 13, n. 5, p. 495-505, 2010.

NARS, F. C. F; FERREIRA, M. A. A.; FISCHER, A. L. A motivação do homem para o trabalho: um estudo sobre o impacto da crise econômica mundial. Rev. Adm. UFSM, Santa Maria, v. 6, n. 2, p. 333-352, jun. 2013.

NASCIMENTO, I. M. Gerenciamento de crises: identificar, planejar e prevenir. Juiz de Fora: Universidade Federal de Juiz de Fora, jul. 2007. 86 p. Monografia (Graduação em Comunicação Social) - Universidade Federal de Juiz de Fora, Juiz de Fora.

OliveIRA, R. F. A. Comunicação no gerenciamento de crises organizacionais. In: CONGRESO DE LA ASOCIACIÓN LATINOAMERICANA DE INVESTIGADORES DE LA COMUNICACIÓn (ALAIC), 21., 6 a 8 ago. 2014, Lima (Peru). Anais... Lima: Alaic, 2014.

ParaskeVas, A.; AltinaY, L. Signal detection as the first line of defence in tourism crisis management. Tourism Management, v. 34, p. 158-171, 2013.

PARASKeVAS, A. et al. Crisis knowledge in tourism: types, flows and governance. Annals of Tourism Research, v. 41, p. 130-152, 2013.

PEARSON, C. M.; ClaIR, J. A. Reframing crisis management. Academy of Management Review, v. 23, n. 1, p. 59-76, 1998. 
PEREIRA, J. M. O que explica a acomodação e a inércia da administração pública no Brasil? UnB, 2014. Disponível em: <http://www.unb.br/noticias/unbagencia/artigo. php?id=675>. Acesso em: 29 nov. 2015.

Rıchardson, R. J. Pesquisa Social: Métodos e técnicas. 3a edição. São Paulo: Atlas, 1999. 334 pp..

RITCHIE, B. W. Chaos, crises and disasters: a strategic approach to crisis management in the tourism industry. Tourism Management, v. 25, p. 669-683, 2004.

RoSA, M. A era do escândalo: lições, relatos e bastidores de quem viveu as grandes crises de imagem. 3. ed. São Paulo: Geração Editorial, 2003.

Santos, R. A. S.; Mello, R. B.; CunhA, C. J. C. A. The leadership process during an organizational crisis. Journal of Operations and Supply Chain Management, v.. 9, n. 1, p. 94-109, jan-jun 2016.

SANTOS, R. A. S. Uma teoria substantiva do processo de liderança em momentos de crise organizacional: o caso das empresas de distribuição de energia elétrica. Florianópolis: Universidade Federal de Santa Catarina, 2012. 333 p. Tese (Doutorado em Engenharia de Produção) - Programa de Pós-Graduação em Engenharia de Produção da Universidade Federal de Santa Catarina, Florianópolis.

Sharpley, R.; CrAVEN, B. The 2001 foot and mouth crisis - rural economy and tourism policy implications: a comment. Current Issues in Tourism, v. 4, n. 6, p. 527537, 2001.

StAcciarinI, I.; CALCAgno, L. Crise do GDF chega ao ápice do risco de colapso financeiro. Correio Brasiliense, Brasília, 14 set. 2015. Cidades. Disponível em: <http://www.correiobraziliense.com.br/app/noticia/cidades/2015/09/14/interna_ cidadesdf,498571/crise-financeira-do-gdf-chega-ao-apce-com-risco-de-colapsofinanceiro.shtml>. Acesso em: 29 nov. 2015.

Sobral, F.; PeCl, A. Administração - teoria e prática no contexto brasileiro. São Paulo: Pearson Prentice Hall, 2008.

TREVISAN, C. Brasil vive combinação de crises fiscal e política, diz Marco Aurélio Garcia. O Estado de São Paulo, Washington, 09 set. 2015. Política. Disponível em: $<$ http://politica.estadao.com.br/noticias/geral,brasil-vive-combinacao-de-crisesfiscal-e-politica--diz-marco-aurelio-garcia,1759376>. Acesso em: 25 nov. 2015.

Vergara, S. C. Métodos de Pesquisa em Administração. 4ạ edição. São Paulo: Atlas, 2010. 277 pp.

Weber, M. Economia e sociedade. Brasília: UnB, 1999. Capítulo III - Os tipos de dominação, p. 139-188. [1922].

\section{Bruna Ribeiro da Silva}

Possui bacharelado em Administração pela Universidade de Brasília (UnB). Contato: brunaribeiro.s.93@gmail.com

\section{Helena Araújo Costa}

Doutora em Desenvolvimento Sustentável. Atualmente é Professora Associada I da Universidade de Brasília (UnB) e Líder do Laboratório de Estudos de Turismo e Sustentabilidade (LETS/UnB). Contato: helenacosta@unb.br 